\title{
O Perfil da Pesquisa Bibliométrica Publicada nas 19 Edições do Congresso Brasileiro de Custos
}

\author{
Marcleide Mendes Barboza \\ Faculdade de Ciências Aplicadas e Sociais de Petrolina - FACAPE \\ Campus Universitário, S/N. Vila Eduardo. Petrolina/PE. CEP: 56328-903 \\ E-mail:mmarcleide@yahoo.com.br
}

Wellington Dantas de Sousa Mestrado em Ciências Contábeis pela Fundação Instituto Capixaba de Pesq. em Contabilidade, Economia e Finanças - FUCAPE Av. Fernando Ferrari, 1358. Boa Vista. Vitória/ES. CEP: 29075-505 E-mail: wellington.bmb@hotmail.com

João Carlos Hipólito Bernardes do Nascimento Doutorado em andamento em Ciências Contábeis pela Universidade Federal do Rio de Janeiro - UFRJ Av. Pedro Calmon, 550. Cidade Universitária. Rio de Janeiro/RJ. CEP: 21941-901 E-mail: jchbn1@gmail.com

Juliana Reis Bernardes Mestrado em Administração de Empresas e Desenvolvimento Empresas pela Universidade Estácio de Sá R. José Clemente, 130. Centro. Niterói/RJ. CEP: 24020-105 E-mail: jureis3d@hotmail.com

Josaias Santana dos Santos Mestrado em Ciências Contábeis pela Fundação Instituto Capixaba de Pesq. em Contabilidade, Economia e Finanças - FUCAPE Campus Universitário, S/N. Vila Eduardo. Petrolina/PE. CEP: 56328-903 E-mail: jureis3d@hotmail.com

\section{RESUMO}

O presente artigo teve como propósito analisar o perfil da produção bibliométrica publicada no âmbito do Congresso Brasileiro de Custos no período que compreende os anos de 1994 a 2012. Fazendo uso da análise quantitativa de dados e sendo norteada por levantamento bibliográfico, foram selecionados trinta e cinco artigos que utilizaram a bibliometria para análise da produção científica. A partir de um estudo bibliométrico, os resultados evidenciaram que a pesquisa bibliométrica foi identificada pela primeira vez no ano de 2007, e nos anos seguintes apresentou-se de forma assimétrica, ou seja, não manteve uma regularidade. Notou-se que prevaleceram publicações em coautoria e a predominância de referências a livros, além do mais, sobressai à pesquisa descritiva no período estudado. Como fato relevante, observa-se a não utilização de leis bibliométricas (por exemplo, Lotka, Bradford e Zipf) em $80 \%$ dos artigos. A produção 
O Perfil da Pesquisa Bibliométrica Publicada nas 19 Edições do Congresso Brasileiro de Custos Marcleide Mendes Barboza, Wellington Dantas de Sousa, João Carlos Hipólito Bernardes do

Nascimento,Juliana Reis Bernardes,Josaias Santana dos Santos

bibliométrica na área contábil publicada no Congresso Brasileiro de Custos encontra-se em fase de amadurecimento, totalizando um número máximo de duas publicações por autor como constatado. E, por fim, observa-se a variabilidade das temáticas abordadas dentro do período pesquisado, em que a bibliometria se fez presente em dez áreas temáticas.

Palavras-chave: Bibliometria. Produção Científica. Congresso Brasileiro de Custos.

The profile of the Bibliometric Research Published in 19 editions of the Brazilian
Congress of Costs

\section{ABSTRACT}

This article aimed to analyze the profile of the bibliometric production published in the Brazilian Congress of Costs in the period comprising the years 1994 to 2012. Making use of quantitative data analysis and being guided by literature, thirty were selected and five articles that used bibliometrics to analyze the scientific production. From a bibliometric study, the results showed that the bibliometric research was first identified in 2007 , and in the following years presented asymmetrically, i.e. not maintained a regular basis. It was noted that prevailed publications in co-authorship and the predominance of references to books, moreover, stands descriptive research the study period. As material fact observed the non-use of bibliometric laws (for example, Lotka, Bradford and Zipf) in $80 \%$ of articles. The bibliometric production in accounting published in the Brazilian Congress of Costs is maturing phase, totaling a maximum of two publications by author as found. Finally we observe the variability of the subjects addressed within the period surveyed, bibliometrics was present in ten thematic areas.

Keywords:Bibliometrics. Scientific Production. Brazilian Congress of Costs.

\section{INTRODUÇÃO}

Até meados do século XIX, a Contabilidade apresentava um cunho estritamente técnico, com a predominância da personificação dos guardas livros, de aspecto puramente pragmático. Nessa época, as atividades didáticas da ciência contábil ocorriam em outros cursos diversos sem a devida regulamentação da doutrina de contabilidade (PELEIAS et al., 2007). Entretanto, diante da necessidade de atualizações por parte das organizações, a contabilidade torna-se ferramenta 
O Perfil da Pesquisa Bibliométrica Publicada nas 19 Edições do Congresso Brasileiro de Custos Marcleide Mendes Barboza, Wellington Dantas de Sousa, João Carlos Hipólito Bernardes do

Nascimento,Juliana Reis Bernardes,Josaias Santana dos Santos

fundamental para auxiliar gestores no processo de tomada de decisão evidenciando sua relevância e valorização (OLIVEIRA; ARAGÃO, 2011).

A pesquisa bibliométrica em contabilidade surge impulsionada pela necessidade de instigar o avanço do conhecimento humano com a divulgação de informações relevantes para a comunidade científica. Bufrem e Prates (2005) descrevem a bibliometria como a impressão de signos matemáticos e estatísticos a obras, devendo ser empregado nos mais variados estudos que quantifica o processo da comunicação escrita.

$\mathrm{Na}$ concepção de Leite Filho (2006), a produção científica na área contábil é marcada fortemente no século $X X$, incentivada, sobretudo, pelas mudanças sociais e econômicas ocorridas na sociedade contemporânea. Indica como fator predominante do aumento da produção científica o grande número de programas de pós-graduação. Leite Filho, Paulo Júnior e Siqueira (2007, p. 2) fazem referência à importância que a universidade exerce na iniciação científica de pesquisadores "a universidade é, portanto, o lócus por excelência onde essa produção é gerada [...]".

Contemporaneamente, os estudos acerca da bibliometria mostram-se em destaque tanto no espaço acadêmico, quanto no organizacional, tendo como objetivo viabilizar segmentos mais favoráveis e nortear subsídios para o setor da produção científica. Destacando pesquisadores e, ao mesmo tempo, instituições mais abordadas, regiões ou países que mais desenvolveram produções. De importância fundamental para a ciência da informação, a bibliometria destaca-se como uma ferramenta indispensável na análise da produção científica de um país, isto porque, os dados constantes nos estudos elaborados, revelam o nível de avanços ocorridos em uma área específica do conhecimento (SOUZA; FARIA, 2011).

Segundo Oliveira e Carvalho (2008), a pesquisa bibliométrica cresce em diversas áreas do conhecimento, em uma busca feita no Google acadêmico utilizando a palavrachave bibliometria foram encontrados 2.530 trabalhos. Em 2013, a mesma busca resultou em 7.860 trabalhos. Vários estudos bibliométricos em contabilidade foram publicados ultimamente e têm se tornado tão frequentes que são poucos pesquisadores 
O Perfil da Pesquisa Bibliométrica Publicada nas 19 Edições do Congresso Brasileiro de Custos Marcleide Mendes Barboza, Wellington Dantas de Sousa, João Carlos Hipólito Bernardes do

Nascimento,Juliana Reis Bernardes,Josaias Santana dos Santos

que não possuem em seu lattes algum tipo de trabalho bibliométrico (SPLITTER; ROSA, 2012). Diante do exposto, é possível verificar que houve um aumento significativo das publicações relacionadas à bibliometria, este fenômeno ocorreu, principalmente, pela veiculação desses trabalhos através de periódicos e eventos científicos.

A pesquisa contábil brasileira desempenhada por docentes e discentes despertam a atenção, para disseminação dos estudos em periódicos e eventos científicos. Valorizando-se os aspectos desses meios de proliferação, busca-se visualizar meios que objetive publicações com um nível significativo de qualidade, destaca-se a importância da divulgação da produção científica como fator relevante para a ciência contábil (OLIVEIRA; CARVALHO, 2008).

Para se mensurar com qualidade e quantidade a produção de artigos científicos publicados sobre determinado tema, faz-se uso do estudo bibliométrico, sendo essa técnica de fundamental importância, pois destaca os autores envolvidos nesse processo, que por sua vez são estudiosos que colaboram para engrandecer a ciência. No segmento da disciplina contábil, os aprendizados bibliométricos, são conduzidos com o propósito de evidenciar trabalhos em revistas e Congressos (BASTOS; HEIN; FERNANDES, 2006).

Segundo Barbosa et al. (2008), é significativo para o desenvolvimento do estudo bibliométrico a utilização de parâmetros que contribuam de forma mais adequada para a realização dos trabalhos, tais parâmetros são denominados como Leis Bibliométricas, mais especificamente, Leis de Lotka, Bradford e Zipf.

Sob a abordagem da bibliometria, o presente estudo buscou identificar aspectos relevantes da pesquisa bibliométrica publicada no Congresso Brasileiro de custos, no período de 1994 a 2012. E para que possam ser compreendidos dentro de suas particularidades, questiona-se: qual o perfil da produção científica bibliométrica publicada nas 19 edições do Congresso Brasileiro de Custos?

A metodologia adotada com o propósito de responder a problemática de estudo é a pesquisa quantitativa que está intimamente ligada a bibliometria. Ambas possuem o 
O Perfil da Pesquisa Bibliométrica Publicada nas 19 Edições do Congresso Brasileiro de Custos Marcleide Mendes Barboza, Wellington Dantas de Sousa, João Carlos Hipólito Bernardes do

Nascimento,Juliana Reis Bernardes,Josaias Santana dos Santos

mesmo intuito de obter indicadores quantitativos da produção científica. "A bibliometriaé amplamente utilizada para quantificar os processos de comunicação escrita" (SAES, 2000, p. 11).

Segundo Filho, Junior e Siqueira (2007, p. 4), "o princípio da bibliometria é analisar a atividade científica pelo estudo quantitativo das publicações". Como técnica quantitativa, busca embasamento teórico nas leis e princípios bibliométricos pormenorizando e delineando os caminhos que deverão ser percorridos para mapear a produção científica (VIEIRA; HORI; GUERREIRO, 2008).

A pesquisa bibliométrica está sedimentada na bibliografia apresentada no Congresso Brasileiro de Custos e tem como amostra 35 artigos selecionados dentro de um universo de 3.346 publicações aprovadas de acordo com os padrões do evento. Em 2013, o Congresso foi classificado pela Qualis/Capes na Categoria E1 pontuação máxima tratando-se de Congressos e eventos científicos. Para Santos, Lima e Martins (2009), todo estudo científico deve estar estruturado em análises literárias que repousam credibilidade, assim, as fontes bibliográficas são reconhecidas como métodos bibliográficos, pois darão suporte aos pesquisadores no decorrer dos seus trabalhos científicos.

Neste sentido, é plenamente aceitável verificar certas peculiaridades, de abordagens utilizadas na estruturação e formação do conhecimento. De acordo com Oliveira e Boente (2012), a inovação da tecnologia é condição primordial para a evolução da pesquisa bibliométrica, tornando-se uma ferramenta necessária para auxiliar o pesquisador na busca de dados que possam dar suporte ao campo da pesquisa científica e da propagação do conhecimento.

Para Macedo, Casa Nova e Almeida (2009, p. 92), pesquisas bibliométricas se justificam por "possibilitarem conhecer o estágio em que a pesquisa se encontra em determinada área". Nestes termos, o estudo mostra-se relevante por fornecer dados que identificam a trajetória da pesquisa bibliométrica publicada em 19 anos. Assim, o presente estudo se justifica nessa necessidade de analisar o perfil dos artigos bibliométricos publicados no âmbito do Congresso Brasileiro de Custos, proporcionando 
O Perfil da Pesquisa Bibliométrica Publicada nas 19 Edições do Congresso Brasileiro de Custos Marcleide Mendes Barboza, Wellington Dantas de Sousa, João Carlos Hipólito Bernardes do

Nascimento,Juliana Reis Bernardes,Josaias Santana dos Santos

ao meio acadêmico uma visão geral de como se encontra a produção científica, servindo para orientar a comunidade científica no aprimoramento da pesquisa bibliométrica.

O objetivo desse trabalho é analisar as produções científicas, detectando através da Bibliometria as características de produção, de autoria e de metodologia de estudo, constatando a utilização de técnicas bibliométricas nos artigos selecionados, e traçar o perfil bibliométrico das pesquisas publicadas nos anais do Congresso Brasileiro de Custos (CBC).

O estudo está estruturado em seções, disposta da seguinte forma. A primeira diz respeito à introdução, a segunda trata do referencial teórico que foi estruturado em quatro tópicos: Contextualização sobre bibliometria, bibliometria aplicada à pesquisa em contabilidade e pesquisa sobre estudos bibliométricos e histórico sobre o $\mathrm{CBC}$, já a terceira apresenta a metodologia, a quarta compreende a análise de dados e finalizando $o$ ato com a conclusão.

\section{REVISÃO DE LITERATURA}

\subsection{Breve contextualização sobre Bibliometria}

Os gregos em tempos remotos possuíam um método que determinava a extensão dos manuscritos, tornando o processo de interpretação de textos mais hábil, pois evitava supressões e também facilitaria na determinação do preço do trabalho e pagamento (PINTO; SILVA; FILHO, 2009).

A bibliometria, como um método de pesquisa, está em contínuo desenvolvimento de sua trajetória, foi utilizada pela primeira vez em 1934, por Paul Otlet em sua obra Traité de Documentatión, onde faz referência a expressão bibliométrie. $O$ termo veio a se repetir em 1948, na conferência de Atlas Sonoro das Línguas Indígenas do Brasil (ASLIB), pelo indiano Ranganathan que indicava uma área que intitulou biblioteconometria, fundamentado pela quantidade de números com os quais lidam as 
O Perfil da Pesquisa Bibliométrica Publicada nas 19 Edições do Congresso Brasileiro de Custos Marcleide Mendes Barboza, Wellington Dantas de Sousa, João Carlos Hipólito Bernardes do

Nascimento,Juliana Reis Bernardes,Josaias Santana dos Santos

bibliotecas. Em 1969, Alan Pritchard difundiu o uso da palavra bibliometria em substituição ao termo bibliografia estatística (VANTI, 2002).

No Brasil, os estudos bibliométricos multiplicaram-se rapidamente a partir da década de 1970. Principalmente, após a utilização da bibliometria pelo Instituto Brasileiro de Bibliografia e documentação - (IBBD), fundado em 1954 para apoiar o controle bibliográfico. Hoje, denominado Instituto Brasileiro de Informação Científica e Tecnológica (IBICT), a biblioteca digital brasileira de teses e dissertações tem como objetivo a disseminação do conhecimento e acesso à informação. Contudo, na década de 1980 houve um declínio no interesse pela bibliometria, esse interesse foi retomado com êxito na década de 1990, devido às possibilidades de uso do computador (ARAÚJO, 2006).

Conforme Silva et al. (2012, p. 3), "o termo bibliometria é derivado da fusão do sufixo "metria" com bibliografia, informação, ciência e biblioteca, respectivamente, são análogos ou muito próximos em sua natureza, objetivos e aplicações". Estuda a produção científica já publicada e dentre os seus objetivos encontra-se a disseminação e acesso a informação escrita de determinada área de conhecimento (GOMES et al., 2007).

A bibliometria é um instrumento que comporta mapear e gerar indicadores de tratamento e gestão da informação e do conhecimento, como ferramenta estatística age, principalmente, em sistemas de informação e de comunicação científica e tecnológica, essencial ao planejamento, avaliação e gestão da ciência e da tecnologia, de uma determinada comunidade científica (GUEDES; BORSCHIVER, 2005).

Uma das abordagens da pesquisa bibliométrica dentro do seu universo de atuação é o fato de padronizar processos, promovendo a divulgação de informações científicas que sejam relevantes e que servirão de fonte de pesquisa para interessados em determinada área do conhecimento (ROZA; MACHADO; QUINTANA, 2011).

Café e Bräscher (2008) contribuíram afirmando que a bibliometria em conjunto com leis e princípios bibliométricos, aplicados a processos estatísticos e matemáticos, tendem a mapear a produtividade científica de periódicos e autores que estão 
O Perfil da Pesquisa Bibliométrica Publicada nas 19 Edições do Congresso Brasileiro de Custos Marcleide Mendes Barboza, Wellington Dantas de Sousa, João Carlos Hipólito Bernardes do Nascimento,Juliana Reis Bernardes,Josaias Santana dos Santos

envolvidos no processo de informação. Para cada extensão dos métodos aplicados a bibliometria, são adotadas, respectivamente, leis inerentes ao modo de pesquisa desenvolvida. São elas: Lei Bradford (lei da dispersão), Lei de Lotka (lei do quadrado inverso) e Lei de Zipf (lei do mínimo esforço).

Formulada no ano de 1926, a Lei de Lotka, tomou como base um estudo sobre a produção científica de vários pesquisadores, partindo de uma contagem de autores na Chemical Abstracts, assim, Lotka concluiu que "uma larga proporção da literatura científica é produzida por um pequeno número de autores, e um grande número de pequenos produtores se iguala, em produção, ao reduzido número de grandes produtores" (ARAÚJO, 2006, p. 13-14-16).

Segundo Araújo (2006), o estudo que Bradford realizou no ano de 1934 com uma série de estudos permitiram formular a lei da dispersão (considerada a segunda lei bibliométrica) que incide sobre conjuntos de periódicos, onde o pesquisador percebeu numa coleção de periódicos sobre geofísica, a existência de um núcleo menor de periódicos relacionados em maior proximidade "ao assunto e um maior núcleo relacionados de maneira estreita, sendo que o número de periódicos em cada zona aumento, enquanto a produtividade diminui. A terceira das leis Bibliométricas clássicas é a lei de Zipf, formulada em 1949 e que descreve a relação entre palavras num determinado texto" (ARAÚJO, 2006, p. 13-14-16).

Diante do exposto, nota-se que Leis bibliométricas, mais especificamente lei Lotka, Bradford e Zipf, dentre outras citadas no Quadro 1, são relevantes na quantificação da atividade científica de determinada área de conhecimento. 
O Perfil da Pesquisa Bibliométrica Publicada nas 19 Edições do Congresso Brasileiro de Custos Marcleide Mendes Barboza, Wellington Dantas de Sousa, João Carlos Hipólito Bernardes do Nascimento,Juliana Reis Bernardes,Josaias Santana dos Santos

\begin{tabular}{|c|c|c|}
\hline $\begin{array}{l}\text { Leis e princípios } \\
\text { bibliométricos }\end{array}$ & Foco & Principais Aplicações \\
\hline Lei de Bradford & Periódicos & $\begin{array}{l}\text { Mensura a dimensão de determinada área do } \\
\text { conhecimento, é um instrumento útil para a } \\
\text { propagação e descarte de periódicos. }\end{array}$ \\
\hline Lei de Lotka & Autores & $\begin{array}{l}\text { Mensura a produtividade de autores, em uma } \\
\text { determinada área científica. É aplicado na } \\
\text { apreciação da produtividade e grau de relevância } \\
\text { de autores }\end{array}$ \\
\hline Leis de Zipf & Palavras & $\begin{array}{l}\text { Mensura a frequência de ocorrência de palavras } \\
\text { em artigos científicos ou tecnológico. }\end{array}$ \\
\hline $\begin{array}{l}\text { Ponto de transição }(\mathrm{T}) \text { de } \\
\text { Goffman }\end{array}$ & Palavras & $\begin{array}{l}\text { Indexação temática automática de artigos } \\
\text { científicos e tecnológicos }\end{array}$ \\
\hline Colégios Invisíveis & Citações & $\begin{array}{l}\text { Identifica a elite dos pesquisadores em } \\
\text { determinado campo científico }\end{array}$ \\
\hline $\begin{array}{l}\text { Fator de imediatismo ou de } \\
\text { impacto }\end{array}$ & Citações & $\begin{array}{l}\text { Mensura a relevância de artigos com base na } \\
\text { frequência que são citados }\end{array}$ \\
\hline Acoplamento Bibliográfico & Citações & $\begin{array}{l}\text { Mensura o grau de ligação de dois ou mais } \\
\text { artigos }\end{array}$ \\
\hline Co-citação & Citações & $\begin{array}{l}\text { Mensura o grau de ligação de dois ou mais } \\
\text { artigos }\end{array}$ \\
\hline Obsolescência da Literatura & Citações & $\begin{array}{l}\text { Mensura o declínio da literatura no decorrer do } \\
\text { tempo de determinado campo científico }\end{array}$ \\
\hline Vida-média & Citações & $\begin{array}{l}\text { Mensura a vida média de determinado item de } \\
\text { determinado campo do conhecimento }\end{array}$ \\
\hline Lei do Elitismo & Citações & $\begin{array}{l}\text { Mensura o tamanho da elite de determinada } \\
\text { população de autores }\end{array}$ \\
\hline Teoria epidêmica de Goffman & Citações & $\begin{array}{l}\text { Mensura a razão de crescimento e declínio de } \\
\text { determinado campo científico, níveis de } \\
\text { importância de linhas de pesquisa indicando } \\
\text { crescimento ou declínio de determinada área. }\end{array}$ \\
\hline Frente de pesquisa & Citações & $\begin{array}{l}\text { Identificação de um padrão de relação múltipla } \\
\text { entre autores que se citam }\end{array}$ \\
\hline Lei dos $80 / 20$ & $\begin{array}{l}\text { Demanda } \\
\text { da } \\
\text { Informação }\end{array}$ & Composição, ampliação e redução de acervos. \\
\hline
\end{tabular}

Quadro 1: Leis e princípios bibliométricos, seus focos de estudo, principais aplicações e áreas de interesse

Fonte: adaptado de Guedes e Borschiver (2005). 
O Perfil da Pesquisa Bibliométrica Publicada nas 19 Edições do Congresso Brasileiro de Custos Marcleide Mendes Barboza, Wellington Dantas de Sousa, João Carlos Hipólito Bernardes do

Nascimento,Juliana Reis Bernardes,Josaias Santana dos Santos

No que diz respeito aos indicadores bibliométricos, Saes (2000) relata que estão fundamentados em análise estatística de dados quantitativos e são imprescindíveis às atualizações das atividades, justifica a aplicação de indicadores bibliométricos e aponta dois motivos: o primeiro analisar o tamanho, crescimento e distribuição da bibliografia tendo como desígnio tornar superior o processo da informação, documentação e comunicação e o segundo examinar os processos de geração, programação e uso da literatura científica com o propósito de conhecer os dispositivos da investigação enquanto atividade social.

Conforme Vanti (2002, p. 4), "os índices bibliométricos também são utilizados para avaliar a produtividade e a qualidade da pesquisa dos cientistas, por meio da medição com base nos números de publicações e citações dos diversos pesquisadores". Pode-se notar que o uso da bibliometria é uma técnica indispensável na quantificação da produção científica, ressalta-se que esta ferramenta, quando diz respeito aos indicadores dão rumo à pesquisa.

A bibliometria é uma espécie de engrenagem na organização dos conteúdos que faz uso de vários elementos de produção, nos mais variados campos explorados, no bojo dessas vantagens em que se molda este método, pode-se incluir o fato dele "amenizar os elementos de julgamento e produzir resultados quantitativos que tendessem a ser a soma de muitos pequenos julgamentos e apreciações realizadas por várias pessoas" (SANTOS; RAUSCH, 2009, p.6).

Machado (2007) chama atenção para as dificuldades enfrentadas por pesquisadores no Brasil, no entanto atribui papel relevante a bibliometria como ramificação da Ciência da Informação permitindo através de seus indicadores propagarem uma dimensão de determinado conhecimento. Complementa afirmando, que os indicadores vêm requerendo solicitude por parte dos governos e comunidade científica, uma vez que favorece um maior destaque dos estados e municípios, no campo científico e tecnológico. 
O Perfil da Pesquisa Bibliométrica Publicada nas 19 Edições do Congresso Brasileiro de Custos Marcleide Mendes Barboza, Wellington Dantas de Sousa, João Carlos Hipólito Bernardes do

Nascimento,Juliana Reis Bernardes,Josaias Santana dos Santos

Os indicadores bibliométricos são indispensáveis e essenciais para se compreender o movimento de renovação e propagação da ciência e o aperfeiçoamento da política científica e da tecnologia pátria (MUGNAINI; JANNUZZI; QUONIAM, 2004).

\subsection{Bibliometria aplicada à pesquisa científica em Contabilidade}

De acordo com Vey et al. (2008), a ciência contábil desenvolve-se de forma significativa em nosso país, provocadas, sobretudo, pelas mudanças ocorridas sejam no aspecto econômico, assim como no social, elevando de forma considerável, as ofertas do ensino de pós-graduação, intensificando dessa forma a produção de cunho científico. É conhecido que estes fenômenos causaram impactos positivos refletindo e contribuindo para o desenvolvimento da Contabilidade e da própria Ciência da Administração de forma universal.

Portanto, deve-se valorizar o conhecimento adquirido no âmbito da academia como indicador direto da produção e do conhecimento humano a fim de que haja uma maior interação entre professores e alunos graduandos, no sentido de partilhar as descobertas em publicações. É nessa esfera que emerge a bibliometria, impulsionada em detrimento da quantificação por autoria, por modelo de revista, programa, número de citações, dentre outros aspectos (OLIVEIRA et al., 2009).

Segundo Silva et al. (2012), nota-se que tanto nas áreas de Administração, quanto de Economia e Contabilidade, foram empregadas técnicas de estudos bibliométricos por diversos pesquisadores brasileiros, especificamente voltados para 0 segmento de negócios.

Nos últimos anos, tornou-se mais evidente as produções bibliométricas em todos os segmentos da contabilidade, sejam através de eventos ou de periódicos, esses pesquisadores produzem uma quantidade variável de temas e metodologias. Importa apurar de que forma tais pesquisas foram exploradas e quais metodologias empregadas, quais fontes abordadas, isto porque, são a partir desses estudos que se evidenciam os modelos das publicações científicas, dos objetos de estudo utilizados, 
O Perfil da Pesquisa Bibliométrica Publicada nas 19 Edições do Congresso Brasileiro de Custos Marcleide Mendes Barboza, Wellington Dantas de Sousa, João Carlos Hipólito Bernardes do

Nascimento,Juliana Reis Bernardes,Josaias Santana dos Santos

assim como os próprios pesquisadores envolvidos na produção metodológica (SPLITTER; ROSA, 2012).

Nos últimos anos, a produção científica em contabilidade cresceu de forma considerável, e a bibliometria orienta parte dessa produção, que consiste na avaliação quantitativa de artigos, relatórios científicos, entre outros. Dentro desse contexto, destaca-se o trabalho pioneiro realizado por Riccio, Carastan e Sakata (1999) e os estudos desenvolvidos por Frezatti e Borba (2000); Oliveira (2001); Mendonça Neto et al. (2004) e Cardoso et al. (2004). No âmbito internacional, ressaltam-se os estudos bibliométricos de Bricker (1989); Chung et al. (1992); Zeff (1996) e Shields (1997) (THEÓPHILO; IUDÍCIBUS, 2005).

Silva, Oliveira e Filho (2005) contribuíram afirmando que, nos últimos anos, a capacidade da produção científica em contabilidade tem atingido níveis consideráveis, isto porque, verificou-se um maior envolvimento cotidianamente de pesquisadores, discente e docentes comprometidos com a pesquisa, mas, sobretudo, empenhados em compreender todos os acontecimentos que envolvem a ciência contábil.

Lima, Diniz e Silva (2012) relatam a existência de uma série de estudos bibliométricos dirigidos para a área contábil, que chama atenção para a pesquisa divulgada a partir de periódicos que privilegiam a contabilidade, proporcionando assim uma melhor qualidade acerca dos trabalhos apresentados.

Conforme evidenciado por Roza, Machado e Quintana (2011), é de fundamental importância que as descobertas e os achados de cunho científico, sejam difundidos, pois os mesmos colaboram para subsidiar o esclarecimento da sociedade a respeito de determinados tópicos. Nesse sentido, é importante que aconteça a transferência dos conteúdos a outros pesquisadores que se achem entusiasmados sobre o assunto abordado.

Atualmente, tem-se dado mais atenção aos estudos bibliométricos que pretendem avaliar como estão sendo elaboradas e difundidas as pesquisas científicas. Para Cardoso et al. (2005), a prática avaliativa de trabalhos acadêmicos é de suma importância no âmbito científico, pois o ato de mapear, sistematicamente, uma 
O Perfil da Pesquisa Bibliométrica Publicada nas 19 Edições do Congresso Brasileiro de Custos Marcleide Mendes Barboza, Wellington Dantas de Sousa, João Carlos Hipólito Bernardes do

Nascimento,Juliana Reis Bernardes,Josaias Santana dos Santos

produção por meio de reavaliações, utilizando métodos bibliométricos, possibilita uma análise apurada de determinada área do conhecimento.

\subsection{Pesquisas sobre Estudos Bibliométricos}

Ponderando que este artigo apresenta os resultados de uma pesquisa realizada no Congresso Brasileiro de Custos faz-se necessário evidenciar estudos anteriores acerca da pesquisa científica em contabilidade sob a abordagem da bibliometria.

Avelar et al. (2012), em uma pesquisa que teve como objetivo identificar os estudos empíricos publicados em periódicos nacionais entre 2000 e 2009, utilizaram a análise bibliométrica e estatística descritiva para obtenção dos resultados, que demonstraram que há uma tendência contínua e clara de aumento do número de artigos publicados ao longo do tempo.

O estudo, de cunho descritivo com abordagem quantitativa, executado por Machado, Silva e Beuren (2007) por meio da bibliometria, analisou as publicações em periódicos nacionais de contabilidade, tendo como objetivo identificar as características da produção científica de custos, publicadas em periódicos nacionais de contabilidade listados no Qualis/Capes. Os principais achados da pesquisa mostram que as temáticas em custos abordam: métodos de custeio com 23 artigos; custos para planejamento e controle, com 20 artigos; aplicações em custos, com 19 artigos; abordagens contemporâneas, com 15 artigos; e a temática de ensino e pesquisa com 5 artigos.

O trabalho de Freitas et al. (2012) investigou um número de artigos com ocorrência do tema contabilidade ambiental, nas publicações dos periódicos da área contábil. Os autores classificam a pesquisa como quantitativa e qualitativa, realizada por meio de uma análise do tipo survey e método bibliométrico para obtenção dos resultados e concluíram que são escassas as publicações e destacam a aplicabilidade e evidenciação dos fatores ambientais, e as informações sobre Contabilidade Ambiental ainda não são consideradas como relevantes.

Braga, Cruz e Oliveira (2007) buscaram conhecer e analisar a pesquisa científica brasileira na área de contabilidade apresentada no Congresso regional de estudantes 
O Perfil da Pesquisa Bibliométrica Publicada nas 19 Edições do Congresso Brasileiro de Custos Marcleide Mendes Barboza, Wellington Dantas de Sousa, João Carlos Hipólito Bernardes do

Nascimento,Juliana Reis Bernardes,Josaias Santana dos Santos

de Ciências Contábeis do Nordeste (ERECIC-NE) no período de 2004 a 2006, para tanto utilizaram da abordagem bibliométrica para obtenção de dados que foram obtidos através de pesquisa documental. Os autores apontam nos seus resultados que há uma maior concentração de referências bibliográficas de livros e as limitadas consultas a periódicos e demais categorias indicam um posicionamento conservador e convencional.

Moura, Dallabona e Lavarda (2012) apresentaram um estudo sobre o perfil bibliométrico dos artigos publicados sobre o tema orçamento nos Congressos USP de controladoria e contabilidade, ENANPAD, Congresso ANPCONT e Congresso Brasileiro de Custos no período de 2005 a 2009. Os resultados, dispostos através de pesquisa descritiva orientada por estudo bibliométrico, evidenciaram que houve aumento nos artigos relacionados ao tema, sendo que o Congresso Brasileiro de Custos apresenta 61 artigos publicados nessa área do total de 116 analisados.

\subsection{Histórico sobre o Congresso Brasileiro de Custos}

O Congresso Brasileiro de Custos é realizado desde 1994, e possui o status de um dos mais conceituados eventos no segmento contábil nacional, de acordo com a classificação Qualis/Capes nas áreas de Administração e Ciências Contábeis. O Congresso busca oportunizar aos pesquisadores a divulgação da produção técnicocientífica, notadamente, voltada para os setores de gestão estratégica de custos empresarial.

O Congresso pode ser compreendido como sendo um ambiente organizado pelos interessados de uma determinada área da ciência, onde os participantes apresentam suas produções de forma sistematizada, verificando os avanços conquistados através de métodos perfeitamente comprovados. Deste modo pode-se destacar o Congresso Brasileiro de Custos, como um evento realizado anualmente, que possibilita a integração entre alunos e profissionais dos segmentos inerentes a contabilidade. 
O Perfil da Pesquisa Bibliométrica Publicada nas 19 Edições do Congresso Brasileiro de Custos Marcleide Mendes Barboza, Wellington Dantas de Sousa, João Carlos Hipólito Bernardes do Nascimento,Juliana Reis Bernardes,Josaias Santana dos Santos

\section{METODOLOGIA}

O presente estudo buscou identificar o perfil da pesquisa bibliométrica publicada no CBC, através de uma análise bibliométrica. Para Macias-Chapula (1998, p. 134), "a Bibliometria é o estudo dos aspectos quantitativos da produção, disseminação e uso da informação registrada. Desenvolve padrões e modelos matemáticos para medir esses processos, usando seus resultados para elaborar previsões e apoiar tomadas de decisão".

Obteve-se trinta e cinco artigos, utilizando como critério de busca, a seleção de palavras que estivessem vinculadas ao objeto estudado. Os resultados foram alcançados através das palavras bibliometria, produção científica e estudo bibliométrico buscadas no sítio da Associação Brasileira de Custos - ABCustos [http://www.abcustos.org.br/], mediante cadastro de associado vigente. Ressalta-se que o critério adotado foi a presença destas palavras no título, no resumo, nas palavraschave ou metodologia.

A amostra evidencia através da contagem de publicações que em 2007 a técnica foi utilizada pela primeira vez, tendo ocorrido oscilações durante o período de 2007 a 2012, portanto, no período de seis anos a pesquisa bibliométrica apresenta-se de forma assimétrica, variando o número de artigos publicados, com um número mínimo de uma publicação e no máximo treze, nos anos pesquisados. Certifica-se que o ano de 2011 foi o período de excelência da bibliometria dentro do Congresso. Esse fato talvez seja explicado pela evolução da produção científica em contabilidade ao logo do tempo o que estimula o pesquisador a estudar essa trajetória.

O tempo cronológico de 1994 a 2012 foi escolhido para evidenciar que, mesmo não sendo um método recente, a bibliometria somente foi abordada como técnica de pesquisa no $C B C$ no ano de 2007, obtendo uma maior representatividade ao longo dos anos. No que tange a delimitação, os dados foram obtidos da seguinte forma: seleção dos artigos em que aborda a bibliometria, leitura dos resumos e da metodologia, seguida da elaboração de Tabelas com dados obtidos. 
O Perfil da Pesquisa Bibliométrica Publicada nas 19 Edições do Congresso Brasileiro de Custos Marcleide Mendes Barboza, Wellington Dantas de Sousa, João Carlos Hipólito Bernardes do

Nascimento,Juliana Reis Bernardes,Josaias Santana dos Santos

Em relação à abordagem do problema, a pesquisa é relacionada como quantitativa. Sendo a "bibliometria, técnica quantitativa e estatística de medição dos índices de produção e disseminação do conhecimento científico" (ARAÚJO, 2006, p.12). Diante da afirmativa, fica demonstrado que a utilização da análise quantitativa dos dados caminha junto com a bibliometria tendo, no entanto, particularidades distintas (VANTI, 2002).

Quanto aos objetivos, a metodologia utilizada foi à pesquisa descritiva que, segundo Cervo, Bervian e Silva (2007, p.61), "observa, registra, analisa e correlaciona fatos ou fenômenos sem manipulá-los. Procura descobrir, com a maior precisão possível, a frequência com que os fenômenos ocorrem, sua relação e conexão com outros, sua natureza e suas características".

No que diz respeito aos procedimentos, o estudo adotou a bibliografia permitindo ao investigador, conhecer e se aprofundar em uma realidade ou fato, sem que o mesmo necessite se deslocar ao local ou espaço físico pesquisado. De outra forma, possibilita que o estudioso do caso concreto, obtenha o conhecimento de todos os dados necessários ao seu trabalho, através de livros e artigos já publicados que, naturalmente, obedeceram a métodos científicos de produção. (GIL, 2002).

Cervo, Bervian e Silva (2007, p.60) contribuem para o conceito da pesquisa bibliográfica:

A pesquisa bibliográfica explica um problema a partir de referências teóricas publicadas em artigos, livros, dissertações e teses. Pode ser realizada independentemente ou como parte da pesquisa descritiva ou experimental. Em ambos os casos, busca-se conhecer e analisar as contribuições culturais ou científicas do passado sobre determinado assunto, tema ou problema.

Os artigos Científicos publicados nos anais do Congresso Brasileiro de Custos contemplam o universo desta pesquisa quanto aos procedimentos de obtenção de dados bibliográficos, portanto, os dados obtidos através da pesquisa bibliográfica foram analisados quantitativamente através de técnicas bibliométricas. 
O Perfil da Pesquisa Bibliométrica Publicada nas 19 Edições do Congresso Brasileiro de Custos Marcleide Mendes Barboza, Wellington Dantas de Sousa, João Carlos Hipólito Bernardes do Nascimento,Juliana Reis Bernardes,Josaias Santana dos Santos

\section{ANÁLISE DOS DADOS}

Dado o objetivo de mapear o perfil da produção científica dos artigos sob a perspectiva da bibliometria, apresenta-se a análise dos dados. Primeiramente, analisase a contagem de publicações que é uma das técnicas bibliométricas que permite analisar a produção científica fornecendo uma medida inicial do número de trabalho que serão propagadas às comunidades científicas (OKUBO, 1997).

A média de autoria por artigos, no ano de 2011, é a menor encontrada durante todo o período com 2,92, chama-se atenção para o fato que esse foi o ano em que a bibliometria mais se destacou em número de publicações, conforme evidenciado na Tabela 1.

Tabela 1: Formação de autoria dos artigos

\begin{tabular}{|c|c|c|c|c|c|c|c|c|}
\hline $\begin{array}{c}\text { Número de } \\
\text { autores }\end{array}$ & $\mathbf{2 0 0 7}$ & $\mathbf{2 0 0 8}$ & $\mathbf{2 0 0 9}$ & $\mathbf{2 0 1 0}$ & $\mathbf{2 0 1 1}$ & $\mathbf{2 0 1 2}$ & Total & Percentual \\
\hline 1 autor & & & & & 2 & & 2 & $5,71 \%$ \\
\hline 2 autores & & 1 & 1 & 1 & 2 & & 5 & $14,29 \%$ \\
\hline 3 autores & & 1 & & 1 & 5 & 2 & 9 & $25,71 \%$ \\
\hline 4 autores & 1 & & 1 & 3 & 3 & 5 & 13 & $37,14 \%$ \\
\hline 5 autores & & 2 & 1 & 1 & 1 & & 5 & $14,29 \%$ \\
\hline $\begin{array}{c}\text { Não } \\
\text { especificado }\end{array}$ & & 15 & 11 & 22 & 38 & 26 & 116 & $2,86 \%$ \\
\hline $\begin{array}{c}\text { Total de } \\
\text { autores }\end{array}$ & 4 & 4 & 3 & 7 & 13 & 7 & 35 & \\
\hline $\begin{array}{c}\text { Total de } \\
\text { artigos }\end{array}$ & 1 & 3,75 & 3,67 & 3,14 & 2,92 & 3,71 & 3,53 & \\
\hline $\begin{array}{c}\text { Média de } \\
\text { autores por } \\
\text { artigos }\end{array}$ & 4 & & 1 & & & 1 & \\
\hline
\end{tabular}

Fonte: Elaboração própria

Vale ressaltar que o artigo "Estudo bibliométrico da área ensino e pesquisa em gestão de custos: triênio 2007-2009 do Congresso Brasileiro de Custos”, publicado no 
O Perfil da Pesquisa Bibliométrica Publicada nas 19 Edições do Congresso Brasileiro de Custos Marcleide Mendes Barboza, Wellington Dantas de Sousa, João Carlos Hipólito Bernardes do

Nascimento,Juliana Reis Bernardes,Josaias Santana dos Santos

XVII CBC, em 2010, não foi contabilizado na Tabela Formação de autoria dos artigos, porque não especificava a autoria. Necessariamente, esta informação deve ser divulgada no site do Congresso, no entanto, nesse caso específico não foi.

Os achados da pesquisa de Splitter e Rosa (2012), quanto à formação de autoria dos artigos, são compatíveis em relação ao número de artigos em coautoria, com 94\% dos artigos sendo produzidos nessa modalidade. Em relação à quantidade de autores por artigos, os resultados diferem dos encontrados por esta pesquisa com $36 \%$ das publicações reunindo três autores por artigo.

Para análise do Perfil da produtividade de autores, o estudo faz uso da Lei de Lotka, que estabelece o número de autores que fazem $\mathbf{x}$ contribuições em um determinado campo científico é aproximadamente $1 / \mathbf{x}^{2}$ daqueles que fazem uma só contribuição. E que a proporção daqueles que fazem uma única contribuição é de $60,8 \%$ e 15,2\% para apenas duas contribuições, e 6,8\% apenas três contribuições, o que demonstra que segundo a Lei de Lotka (1926), mais de $82 \%$ dos autores, produzem no máximo três artigos e somente menos de $20 \%$ destes tem 4 publicações ou mais. (ALVARADO, 2002).

A Tabela 2 apresenta o número de artigos publicados por autor e compara com o padrão de Lotka. Os resultados mostram que $94,83 \%$ dos autores publicaram apenas 1 artigo, aproximadamente, 35\% a mais dos padrões de Lotka. Os resultados do estudo de Silva et al. (2012) também mostram que os achados da pesquisa em relação à produtividade dos autores diferem com $30 \%$ a mais dos padrões de Lotka. 
O Perfil da Pesquisa Bibliométrica Publicada nas 19 Edições do Congresso Brasileiro de Custos Marcleide Mendes Barboza, Wellington Dantas de Sousa, João Carlos Hipólito Bernardes do Nascimento,Juliana Reis Bernardes,Josaias Santana dos Santos

Tabela 2: Número de artigos por autor

\begin{tabular}{|c|c|c|c|}
\hline $\begin{array}{c}\text { Número de } \\
\text { artigos por autor }\end{array}$ & $\begin{array}{c}\text { Frequência } \\
\text { registrada } \\
\text { de autor }\end{array}$ & $\%$ & $\begin{array}{c}\text { Padrão } \\
\text { Lotka }\end{array}$ \\
\hline 1 artigo & 110 & $94,83 \%$ & $60,8 \%$ \\
\hline 2 artigos & 6 & $5,17 \%$ & $15,2 \%$ \\
\hline 3 artigos & & & $6,8 \%$ \\
\hline 4 artigos & & & $3,8 \%$ \\
\hline 5 artigos & & & $2,4 \%$ \\
\hline 6 artigos & & & $1,7 \%$ \\
\hline 7 artigos & & & $1,2 \%$ \\
\hline Mais de 7 artigos & & & $8,1 \%$ \\
\hline Total & $\mathbf{1 1 6}$ & $\mathbf{1 0 0} \%$ & $\mathbf{1 0 0} \%$ \\
\hline
\end{tabular}

Fonte: Elaboração própria

De acordo com a lei de Lotka, que tem como foco de estudo a produção científica de autores em determinado campo de conhecimento e sua relevância, os autores mais produtivos dentro do CBC são: Antônio Cezar Bornia (UFSC, 2011/ 2012), Carlos Alberto Pereira (USP, 2011/2012), Débora Gomes Machado (FURB, 2012), Ilse Maria Beuren (FURB, 2011), Silvio Paula Ribeiro (UFMS, 2011), Vidigal Fernandes Martins (EAESP/FGV/UFU, 2011/2012) todos com dois trabalhos publicados no CBC.

A Tabela 3 apresenta os tipos de referências bibliográficas utilizadas pelos autores que publicaram no Congresso. Especificando o tipo de bibliografia foram encontrados livros, teses e dissertações, periódicos, jornais, eventos científicos, endereços eletrônicos, leis e Decretos. 
O Perfil da Pesquisa Bibliométrica Publicada nas 19 Edições do Congresso Brasileiro de Custos Marcleide Mendes Barboza, Wellington Dantas de Sousa, João Carlos Hipólito Bernardes do Nascimento,Juliana Reis Bernardes,Josaias Santana dos Santos

Tabela 3: Tipos de Referências Bibliográficas

\begin{tabular}{|c|c|c|c|c|c|c|c|c|c|}
\hline \multirow{2}{*}{$\begin{array}{c}\text { Tipo de } \\
\text { bibliografia }\end{array}$} & & \multicolumn{8}{|c|}{ Ano } \\
\hline & & 2007 & 2008 & 2009 & 2010 & 2011 & 2012 & Total & $\%$ \\
\hline \multirow[t]{2}{*}{ Livro } & Nacional & 6 & 20 & 28 & 34 & 116 & 53 & 257 & $29,81 \%$ \\
\hline & Internacional & 1 & 3 & 3 & 12 & 31 & 5 & 55 & $6,37 \%$ \\
\hline \multirow{2}{*}{$\begin{array}{c}\text { Teses e } \\
\text { dissertações }\end{array}$} & Nacional & & 7 & 1 & 19 & 12 & 17 & 56 & $6,5 \%$ \\
\hline & Internacional & & & & & & & & \\
\hline \multirow[t]{2}{*}{ Periódicos } & Nacional & 2 & 21 & 14 & 19 & 51 & 32 & 139 & $16,13 \%$ \\
\hline & Internacional & 2 & 4 & 1 & 58 & 41 & 24 & 130 & $15,08 \%$ \\
\hline \multirow{2}{*}{$\begin{array}{c}\text { Anais e } \\
\text { eventos } \\
\text { científicos }\end{array}$} & Nacional & 6 & 9 & 14 & 25 & 102 & 25 & 181 & $21 \%$ \\
\hline & Internacional & & & & 1 & & & 1 & $0,12 \%$ \\
\hline \multirow[t]{2}{*}{ Jornais } & Nacional & & & 1 & & & & 1 & $0,12 \%$ \\
\hline & Internacional & & 1 & & & 1 & & 2 & $0,23 \%$ \\
\hline \multirow{2}{*}{$\begin{array}{l}\text { Endereços } \\
\text { eletrônicos }\end{array}$} & Nacional & & 6 & 3 & 3 & 16 & 4 & 32 & $3,71 \%$ \\
\hline & Internacional & & & & & & & & \\
\hline $\begin{array}{c}\text { Leis e } \\
\text { Decretos }\end{array}$ & & & & 2 & 1 & 1 & 4 & 8 & $0,93 \%$ \\
\hline Total & & 17 & 71 & 67 & 172 & 371 & 164 & 862 & $100 \%$ \\
\hline
\end{tabular}

Fonte: Elaboração própria

É importante ressaltar que, leis e decretos fizeram-se presentes nas referências citadas nos anos de 2009 a 2012, com participação de 0,93\%. Os resultados quanto às referências mostram que do total de 862 referências, 29,81\% são originadas de livros nacionais, seguidas de anais e eventos científicos nacionais com $21 \%$, periódicos nacionais com $16,13 \%$, e com $6,5 \%$ teses e dissertações, totalizando os demais $26,56 \%$. Em todo o período pesquisado consta apenas de três referências a jornais, chama-se atenção para o número de referências a periódicos internacionais com $15,08 \%$. A partir da análise das 862 referências, pode-se relacionar um total de artigos e obter uma média por artigo de 24,64 citações.

Percebeu-se o cuidado dos autores na seleção de anais e eventos científicos como também dos periódicos mais citados, dentre eles, pode-se notar alguns dos mais 
conceituados de acordo com a qualificação da Qualis/Capes. Buscando acrescentar a análise anterior, segue eventos científicos e periódicos mais citados no CBC acerca dos estudos bibliométricos, conforme o Gráfico 1.

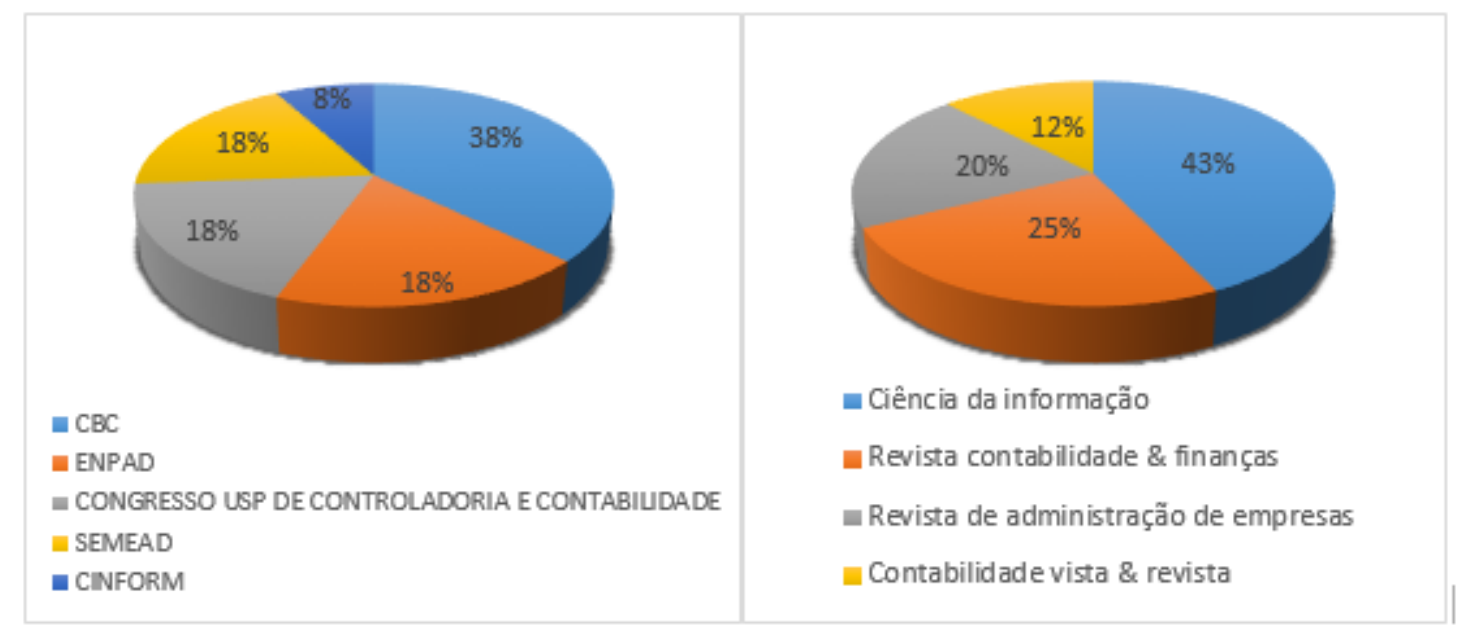

Gráfico 1: Eventos científicos e periódicos mais citados Fonte: Elaboração própria

Em relação ao volume de artigos publicados por área temática no Congresso Brasileiro de Custos no período de 1994 a 2012, pode-se notar que a bibliometria foi investigada em dez áreas temáticas, tendo maior destaque os seguintes temas, metodologias de ensino e pesquisas em custos e ensino e pesquisa na gestão de custos representando um percentual de $28,57 \%$ e $20 \%$, respectivamente.

Constatou-se uma diversidade de temas abordados pela bibliometria. Segundo Splitter e Rosa (2012), a pesquisa bibliométrica evolui no campo contábil, e essa crescente trajetória mostra-se na variabilidade de temas que a bibliometria aborda. Os resultados obtidos por Oliveira e Boente (2002) denotam que as áreas mais destacadas na pesquisa contábil são; contabilidade gerencial, teoria contábil e educação e pesquisa contábil. Na Tabela 4 é apresentado o volume de artigos publicados por área temática. 
O Perfil da Pesquisa Bibliométrica Publicada nas 19 Edições do Congresso Brasileiro de Custos Marcleide Mendes Barboza, Wellington Dantas de Sousa, João Carlos Hipólito Bernardes do Nascimento,Juliana Reis Bernardes,Josaias Santana dos Santos

Tabela 4: Volume de artigos publicados por área temática

\begin{tabular}{|c|c|c|c|c|c|c|c|c|}
\hline Área Temática & స్ํ․ & 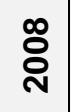 & 옹 & 웅 & $\overline{\aleph^{2}}$ & 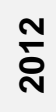 & $\begin{array}{l}\bar{\pi} \\
\stackrel{0}{0}\end{array}$ & $\%$ \\
\hline Metodologias de ensino e pesquisas em custos & & & & & 6 & 4 & 10 & $28,57 \%$ \\
\hline Ensino e pesquisa na gestão de custos & & 2 & 2 & 3 & & & 7 & $20 \%$ \\
\hline Abordagens contemporâneas de custos & & & & & 4 & 2 & 6 & $17,14 \%$ \\
\hline Gestão do conhecimento e capital intelectual & 1 & & 1 & 1 & & & 3 & $8,57 \%$ \\
\hline Controladoria & & 1 & & 1 & & & 2 & $5,71 \%$ \\
\hline $\begin{array}{l}\text { Custos como ferramenta para o planejamento e gestão } \\
\text { de custos }\end{array}$ & & & & & 2 & & 2 & $5,71 \%$ \\
\hline Gestão estratégica de custos & & & & 2 & & & 2 & $5,71 \%$ \\
\hline $\begin{array}{l}\text { Contribuições teóricas para a determinação e a gestão } \\
\text { de custos }\end{array}$ & & & & & 1 & & 1 & $2,85 \%$ \\
\hline Custos aplicados ao setor publico & & & & & & 1 & 1 & $2,85 \%$ \\
\hline Novas tendências aplicadas na gestão de custos & & 1 & & & & & 1 & $2,85 \%$ \\
\hline
\end{tabular}

Fonte: Elaboração própria

As temáticas relacionadas ao ensino e pesquisa quando somadas obtiveram percentuais expressivos (48,57\%). De acordo com Borges et al. (2012), observando a realidade atual, nota-se que existe um ambiente favorável que contempla 0 desenvolvimento tanto do ensino, quanto da pesquisa em contabilidade. A busca do conhecimento através da produção científica deve estar pautada por mecanismos que edifiquem o conhecimento, colocando as universidades como peças fundamentais para o desenvolvimento da ciência.

Analisando questões relacionadas ao ensino e pesquisa nos estudos bibliométricos tem-se os autores (VIEIRA, 2008), (VEY, 2008), (CRUZ, 2009), (OLIVEIRA, 2009), (PASSOS, 2010), (WALTER, 2010), (CRUZ, 2011), (CUSTÓDIO, 2011), (VAZ, 2011), (BEUREN, 2011), (OLIVEIRA, 2011), (MACHADO, 2011), (SOUZA, 2012), (SILVA, 2012), (CARMO, 2012), (LIMA, 2012), entre outros coautores.

Com relação à citação de autores, Macias-Chapula (1998) contribui afirmando que, deve-se existir uma profunda sintonia entre o citando e o citado, pois na busca da 
O Perfil da Pesquisa Bibliométrica Publicada nas 19 Edições do Congresso Brasileiro de Custos Marcleide Mendes Barboza, Wellington Dantas de Sousa, João Carlos Hipólito Bernardes do Nascimento,Juliana Reis Bernardes,Josaias Santana dos Santos

construção de um pensamento, não pode haver distorções ou contradições, acerca do material pesquisado. De outra forma, é possível que sejam observadas lacunas invariáveis, isto porque, surgem, inevitavelmente, as chamadas imprecisões. O Gráfico 2 mapeia os autores mais citados nos artigos publicados.

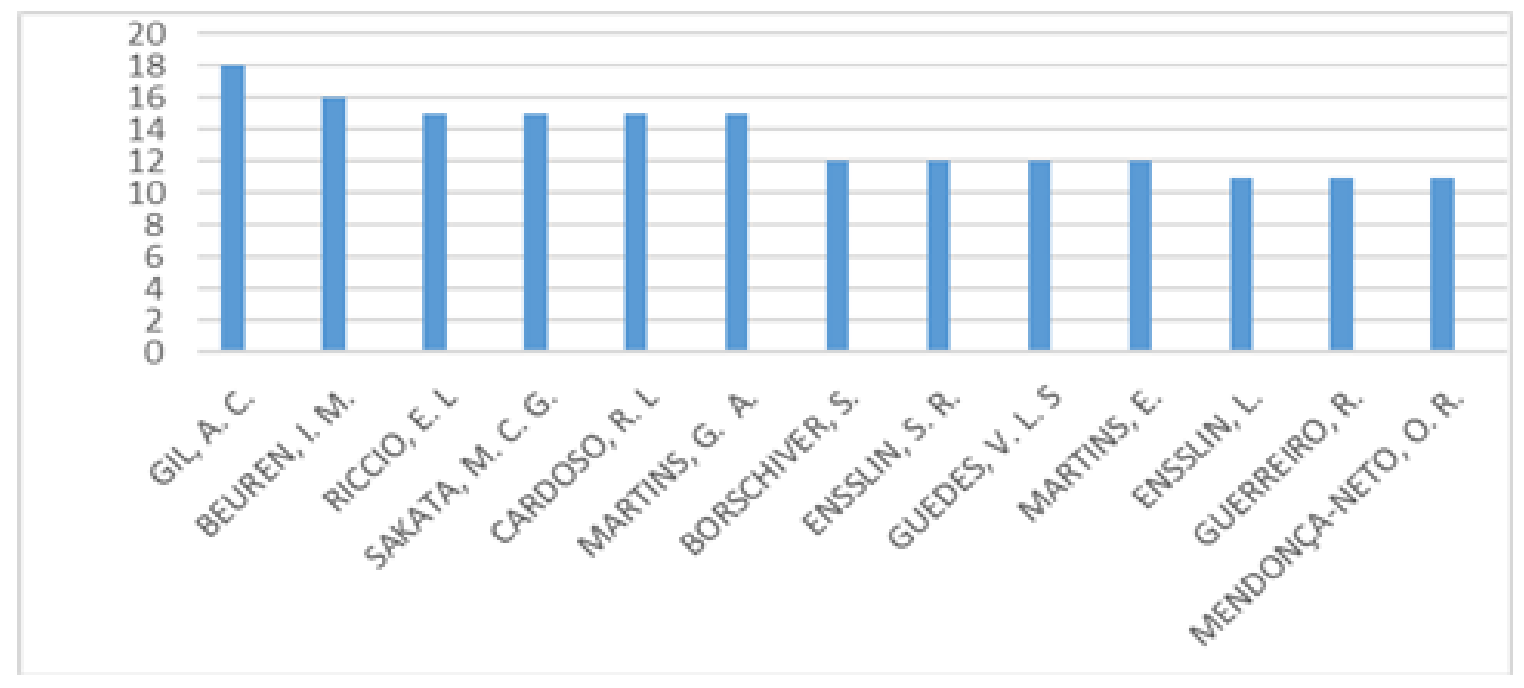

Gráfico 2: Autores mais citados

Fonte: dados da pesquisa (2013)

Dos trinta e cinco trabalhos selecionados foram identificados 1.491 autores citados. Um ponto de destaque evidencia-se na quantidade de citações direcionadas para cada autor, pode-se constatar que estes autores são referências no campo de conhecimento abordado. Os autores mais citados foram: Antônio Carlos Gil (USCS) com dezoito trabalhos, Ilse Maria Beuren (FURB/UFPR) com dezesseis trabalhos, Edson Luiz Riccio (FEA/USP), Marici Cristine GramachoSakata (USP/UNISINOS/UFSCAR), Ricardo Lopes Cardoso (FGV/USP) e Gilberto de Andrade Martins (USP/UFMG) com quinze trabalhos, Suzana Borschiver (UFRJ), Sandra Rolim Ensslin (UFSC/UNISUL), Vânia Lisboa da Silveira Guedes (UFRJ/UNIRIO) e Eliseu Martins (FEA/USP) com doze trabalhos, e por fim Leonardo Ensslin (UFSC/UNISUL), Reinaldo Guerreiro (USP) e Octávio Ribeiro de Mendonça Neto (USP) com onze trabalhos. Todos dentro do universo de trinta e cinco artigos publicados. 
Mesmo com a evolução do conhecimento científico ao longo do tempo, determinadas obras são referências que não perdem sua importância como referencial histórico. Todavia, a ciência tende a se renovar e nesse movimento contínuo de transformação gradual surgem novos pesquisadores dispostos a contribuir para o engrandecimento da ciência (ROSA et al., 2010).

A presente pesquisa fez uso da contagem completa de autores, ou seja, quando cada autor é mencionado por sua colaboração. A análise bibliométrica da contagem de autores, segundo Alvorado (2002), pode ocorrer de três formas contagem direta, completa e ajustada.

O Gráfico 3 evidencia um resumo do caráter metodológico utilizado pelos pesquisadores.

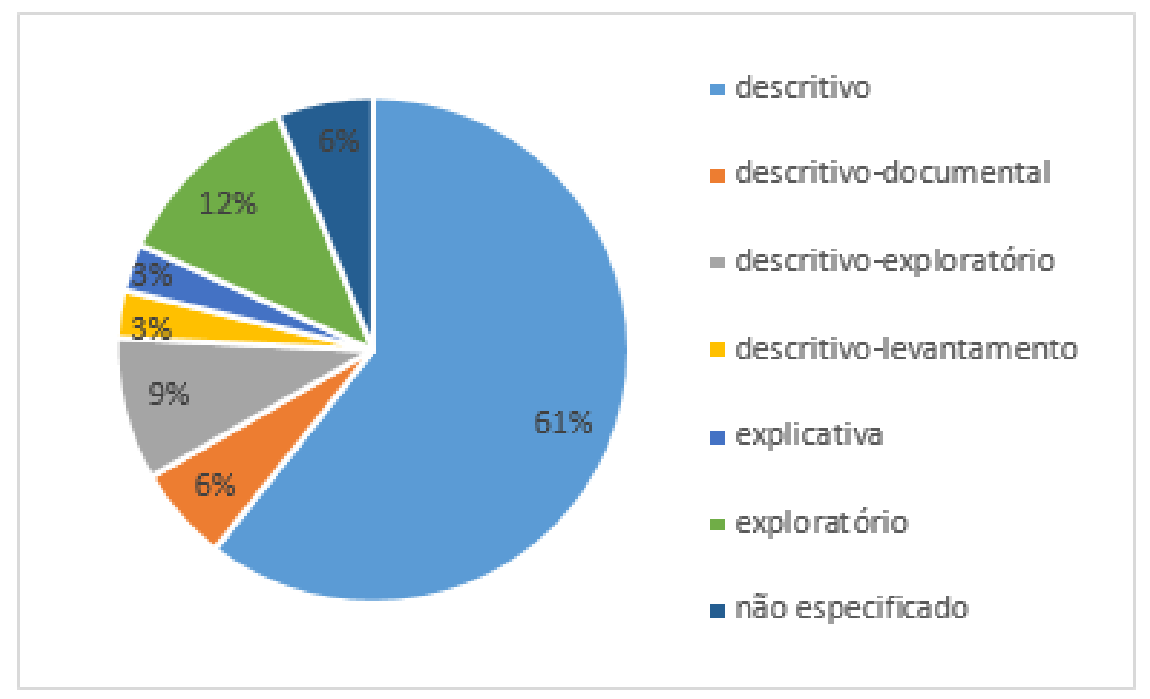

Gráfico 3: Caráter metodológico dos estudos

Fonte: Elaboração própria

Observa-se que predomina a pesquisa descritiva, com $61 \%$ do total de artigos publicados, seguida pela pesquisa-exploratória, com 12\%, descritivo-exploratória $9 \%$, não especificaram e descritivo documental com $6 \%$, descritivo-levantamento e explicativa com $3 \%$. Corroborando com tal fato, temos a pesquisa de Almeida et al. 
O Perfil da Pesquisa Bibliométrica Publicada nas 19 Edições do Congresso Brasileiro de Custos Marcleide Mendes Barboza, Wellington Dantas de Sousa, João Carlos Hipólito Bernardes do Nascimento,Juliana Reis Bernardes,Josaias Santana dos Santos

(2009) mostrando que $80 \%$ dos artigos pesquisados são de caráter descritivo, seguidas por exploratória e explicativa.

Quanto às leis bibliométricas, o estudo revela que, dos trinta e cinco trabalhos publicados no $\mathrm{CBC}$, vinte e oito deles não utilizam leis bibliométricas e apenas sete aplicaram a técnica. Três trabalhos utilizaram duas leis conjuntas e quatro trabalhos utilizaram apenas uma lei. Vale ressaltar que a lei de Lotka foi a mais relevante, abordada em cinco trabalhos, seguida por Bradford com três e Zipf com dois.

Splitter e Rosa (2012), analisando a utilização de leis bibliométricas, enxergaram que apenas um entre dez trabalhos fez uso de leis bibliométricas. Ressalta que, esses trabalhos não estão em conformidade com a proposta da bibliometria. A seguir, o Gráfico 4 mostra a abordagem de Leis bibliométricas publicadas nos artigos do CBC.

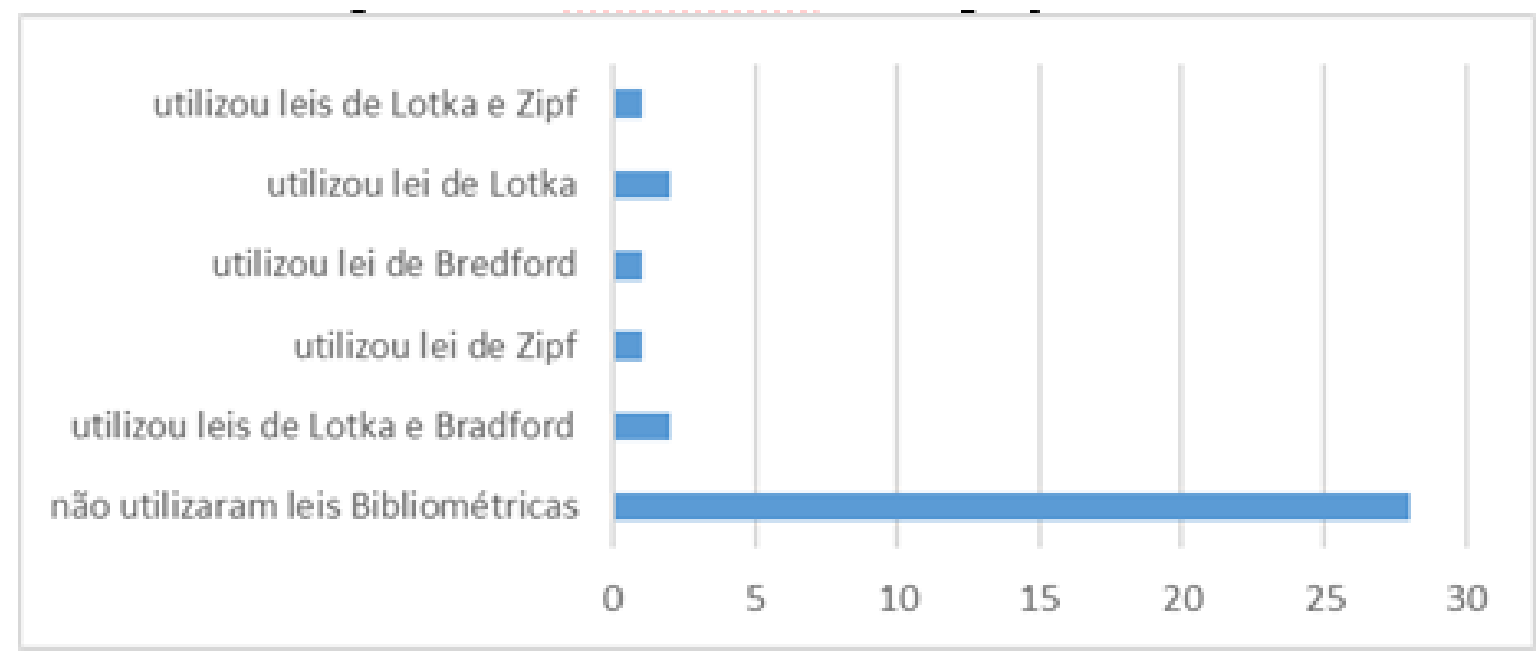

Gráfico 4: Abordagem de Leis Bibliométricas nos artigos publicados Fonte: Elaboração própria

O perfil da pesquisa bibliométrica, quanto aos autores, será estabelecido a partir da instituição de vínculo e titulação, seguida por gênero dos autores. Com relação ao vínculo institucional, foi feita uma classificação de acordo com os autores que utilizaram a bibliometria em seus estudos e sua produtividade dentro do CBC. Dentre as instituições que mais se destacaram dentro da amostra, obteve notoriedade a FURB, 
O Perfil da Pesquisa Bibliométrica Publicada nas 19 Edições do Congresso Brasileiro de Custos Marcleide Mendes Barboza, Wellington Dantas de Sousa, João Carlos Hipólito Bernardes do Nascimento,Juliana Reis Bernardes,Josaias Santana dos Santos

produzindo quatro artigos abordando a técnica bibliométrica. Com relação à titulação dos autores mais produtivos, verificou-se um fato relevante, constata-se que todos são mestres ou doutores, conforme apresentado na Tabela 5. Na pesquisa realizada por Lima, Diniz e Silva (2012) os resultados mostram que 43\% dos autores possuíam título de mestre ou doutor.

Tabela 5: Autores, instituições e titulação dos mais produtivos nas 19 edições do CBC.

\begin{tabular}{|c|c|c|c|}
\hline Autores & Instituições & Titulação & Total de artigos \\
\hline BEUREN, I. M. & FURB & Doutorado & 39 \\
\hline BORNIA, A. C. & UFSC & $\begin{array}{l}\text { Mestrado, } \\
\text { Doutorado }\end{array}$ & 36 \\
\hline MACHADO, D. G. & FURB & Doutorado & 8 \\
\hline MARTINS, F. V. & EAESP/FGV/UFU & Doutorado & 11 \\
\hline RIBEIRO, S. P. & UFMS & Mestrado & 15 \\
\hline PEREIRA, C. A. & USP & $\begin{array}{l}\text { Mestrado, } \\
\text { Doutorado }\end{array}$ \\
\hline
\end{tabular}

Fonte: Elaboração própria

Com relação ao gênero de autores e coautores, dentro do universo pesquisado o gênero de autoria os dados da pesquisa mostram-se em equilíbrio. No entanto, há uma concentração maior de autores do gênero masculino em relação ao feminino, em que o primeiro se sobressai com $52 \%$ e o segundo com $48 \%$ das publicações.

Os mesmos dados referentes ao estudo por gênero foram investigados no estudo de Gomes et al. (2007), evidenciando certo equilíbrio entre o quantitativo de homens e mulheres inseridos no contexto da pesquisa contábil, apresentado percentuais de $44 \%$ para as mulheres e $56 \%$ para os homens.

\section{CONSIDERAÇÕES FINAIS}

O presente estudo teve como objetivo mapear as produções científicas apresentadas no Congresso Brasileiro de Custos, no período de 1994 a 2012, sob a 
O Perfil da Pesquisa Bibliométrica Publicada nas 19 Edições do Congresso Brasileiro de Custos Marcleide Mendes Barboza, Wellington Dantas de Sousa, João Carlos Hipólito Bernardes do

Nascimento,Juliana Reis Bernardes,Josaias Santana dos Santos

perspectiva da bibliometria. Inicialmente, buscou-se analisar a evolução cronológica dos artigos. Dentre os 3.346 artigos publicados nas 19 edições do CBC, 35 artigos trazem a bibliométrica como foco de estudo.

Em atenção ao número de artigos publicados, verificou-se que, nos anos anteriores ao de 2010, a abordagem bibliométrica foi inexpressiva com oito publicações em dezesseis anos de Congresso, no entanto, o ano de 2011 foi o ápice da bibliometria. Com relação à formação de autoria dos artigos, percebe-se que não é padrão em trabalhos bibliométricos a produção com apenas um autor $(5,71 \%)$, a maioria dos trabalhos são produzidos em coautoria (94,29\%). Quanto à produção de autores, os resultados diferem dos padrões de Lotka com, aproximadamente, 35\% a mais para produção de um único artigo por autor, e com 10\% a mais para dois artigos por autor.

Posteriormente, foi realizada a identificação de palavras-chave mais abordadas pelos autores, prevalecendo à palavra bibliometria com $17 \%$. No que tange aos tipos de referências utilizadas pelos autores, prevalecem às referências nacionais a livros $(29,81 \%)$ seguidas por anais e eventos científicos $(21 \%)$ e periódicos $(16,13 \%)$. Referente às áreas temáticas foi identificado que, a temática de maior destaque trata-se do ensino e pesquisa (48,57\%). Com relação às citações evidencia-se que a média de citações por artigos é de 24,64 e que, dos 35 artigos, Antônio Carlos Gil com 51,43\% e Ilse Maria Beuren com 45,71\% são referências dentro do contexto da produção bibliométrica.

Foi constatado que a produção científica bibliométrica publicada no $\mathrm{CBC}$, quanto à metodologia de pesquisa, é centrada na pesquisa descritiva com $61 \%$. E como fator de relevância, os resultados mostram que $20 \%$ das pesquisas abordaram leis bibliométricas, sendo a lei de Lotka a de maior destaque, utilizada em cinco trabalhos, seguida por Bradford com três e Zipf com dois.

Os achados da pesquisa permitem concluir que estudos bibliométricos são relevantes para a propagação do conhecimento científico. Todavia, deve-se apreciar os indicadores bibliométricos, tendo em vista oportunizar discussões e aprendizados 
O Perfil da Pesquisa Bibliométrica Publicada nas 19 Edições do Congresso Brasileiro de Custos Marcleide Mendes Barboza, Wellington Dantas de Sousa, João Carlos Hipólito Bernardes do

Nascimento,Juliana Reis Bernardes,Josaias Santana dos Santos

acerca dos temas abordados, proporcionando a comunidade científica informações e experiências adquiridas, contribuindo dessa forma para o fortalecimento da pesquisa científica.

Cabe esclarecer que, dentre as limitações do presente estudo, destaca-se o fato do pequeno número de trabalhos publicados voltados para a metodologia bibliométrica. Portanto, diante da amostra não foi possível destacar um autor com um número satisfatório de publicações, sendo o resultado máximo igual a dois artigos por autor.

Como sugestão de novos estudos, recomenda-se a comparação de periódicos para verificar particularidades da pesquisa bibliométrica e sua evolução histórica.

\section{REFERÊNCIAS}

ALVARADO, R. V. (2002). A lei de Lotka na bibliometria Brasileira. Enc. Blibli: Eletr. Bibliotecon. Ci. Inf.; v. 31, n. 2 p.14/20, 2002.

ALMEIDA, K.; FERREIRA, C. C.; OLIVEIRA, R. S.; ALYRIO, R. D.; SALLES, M. B. (2009). Análise da evolução da metodologia utilizadas nos artigos publicados na revista: Contabilidade \& Finança USP. Anais...XII Semead.

ARAÚJO, C. A. (2006). Bibliometria: evolução histórica e questões atuais. Em questão. Porto Alegre, v. 12, n. 1, p. $11-32$, jan./jun.

ARAÚJO, E. A. T.; SILVA, W. A. C. (2010). Pesquisa científica em Contabilidade Gerencial nos ENANPADs de 2003 a 2008*. Universo Contábil, v.6 n.3 p.29-44, jul./set.

AVELAR, E. A.; SANTOS, T. S.; RIBEIRO, L. M. P; OLIVEIRA, C. C. (2012). Pesquisa em Contabilidade: uma análise dos estudos empíricos publicados em periódicos nacionais entre 2000 e 2009. Universo Contábil, v.8 n.3 p. 06-23, jul./set.

BARBOSA, E. T.; ECHTERNACHT, T. H. S.; FERREIRA, D. L.; LUCENA, W.G. L. (2008). Uma análise bibliométrica da Revista Brasileira de Contabilidade no período de 2003 a 2006. Anais... Congresso USP de Iniciação Científica em Contabilidade, 05, 2008, São Paulo. FEA-USP.

BASTOS, E.; HEIN, N.; FERNANDES, F. (2006). Inserção da controladoria em artigos publicados em eventos científicos nacionais. Anais...Simpósio de Excelência em Gestão e Tecnologia. Niterói/RJ. 
BRAGA, J. P.; CRUZ, C. F.; OLIVEIRA, J. R. (2007). Pesquisa contábil no Nordeste: um estudo bibliométrico da produção científica apresentada no Encontro Regional de estudantes de Ciências Contábeis. Anais...Congresso USP de controladoria e contabilidade. São Paulo. FEA/USP.

BORGES, G. F.; AVELAR, E. A.; NASCIMENTO, J. P. B.; MAGRA, F. L. N. (2012). Ensino de Contabilidade: uma análise da produção científica nacional sob a perspectiva da bibliometria e sociometria. Anais...12 $2^{\circ}$ Congresso USP de Controladoria e Contabilidade, São Paulo, junho.

BUFREM, L.; PRATES, Y. (2005). O saber científico registrado e as práticas de mensuração da informação. Ci inf. v.34, n.2 p. 9-25, maio/ago.

CAFÉ, L.; BRÄSCHER, M. (2008). Organização da informação e bibliometria. Enc. Bibli: R. Eletr. Bibliotecon. Ci. Inf., Florianópolis, n. esp. 1ํsem.

CARDOSO, R. L.; MENDONÇA, N. O. R.; RICCIO, E. L.; SAKATA, M. C. G. (2005). Pesquisa Científica em Contabilidade entre 1990 e 2003. Revista de Administração de empresas - RAE, v. 43.

CERVO, A. L.; BERVIAN, P. A.; SILVA, R. (2007). Metodologia científica. 6. ed. São Paulo: Pearson Prentice Hall.

LEITE FILHO, G. A.; PAULO JÚNIOR, J.; SIQUEIRA, R. L. (2007). Revista contabilidade \& finanças USP: uma análise bibliométrica de 1999 a 2006. Anais... 4ํㅜㅇ Congresso de Iniciação Científica da USP. São Paulo: USP.

FREITAS, D. P. S.; QUARESMA, J. C. C.; SCHMITT, S. R. Z.; GONÇALVES, T. L. (2012). Contabilidade ambiental: um estudo bibliométrico em revistas científicas brasileira. Revista Ambiente Contábil, v.4 n.1 p.72-78, jan./jun.

GIL, A. C. (2002). Como elaborar projetos de pesquisa. (4 ed.). Atlas.

GOMES, R. B.; SANTIAGO, H. L. F.; LIMA, A. E. A; GOMES, M. C. S.; FILHOS, J. F. R.; PEDERNEIRAS, M. M. M. (2007). Um estudo sobre a produção Acadêmica em Contabilidade: uma abordagem nos Congressos USP de Iniciação Científica em Contabilidade. Anais... $4^{\circ}$ Congresso de Iniciação Científica da USP. São Paulo: USP.

GUEDES, V. L. S.; BORSCHIVER, S. (2005). Bibliometria: uma ferramenta científica para a gestão da informação e do conhecimento, em sistemas de informação, da comunicação e de avaliação científica e tecnológica. Anais...VI Cinform. Jun. 
O Perfil da Pesquisa Bibliométrica Publicada nas 19 Edições do Congresso Brasileiro de Custos Marcleide Mendes Barboza, Wellington Dantas de Sousa, João Carlos Hipólito Bernardes do Nascimento,Juliana Reis Bernardes,Josaias Santana dos Santos

LEITE FILHO, G. A. (2006). Padrões de Produtividade de Autores em Periódicos de Congressos na Área de Contabilidade no Brasil: um Estudo Bibliométrico. Anais... Congresso USP de Controladoria. São Paulo.

LOTKA, A. J. (1926). The frequency distribution of scientific productivity. Journal of the Washington Academy of Sciences, v. 16, n. 12, p. 317-323.

LIMA, F. D. C.; DINIZ, J. R.; SILVA, D. M. (2012). Perfil da produção Científica em Contabilidade: um comparativo entre os periódicos Contabilidade Vista e Revista e Universo Contábil no período de 2006 a 2010. Anais... XIX Congresso Brasileiro de Custos. Bento Gonçalves/RS.

MACIAS-CHAPULA, C. A. (1998). O papel da informetria e da cienciometria e sua perspectiva Nacional e Internacional. Ciência da informação, v.27, p. 134-140, maio/ago. 1998.

MACEDO, M. A. S.; CASA NOVA, S. P. C.; ALMEIDA, K. (2009). Mapeamento e análise bibliométrica da utilização da análise envoltória de dados (DEA) em estudos de contabilidade e Administração. Contabilidade, Gestão e Governança, v.12 n.3 p. 87101.

MACHADO, D. G.; SILVA, T. P.; BEUREN, I. M. (2012). Produção Científica de Custos: análise das publicações em periódicos Nacionais de Contabilidade sob a perspectiva das redes sociais e da bibliometria. Revista contabilidade e gestão, v.15 n.3 p.3-16.

MACHADO, R. N. (2007). Análise Cientométrica dos estudos bibliométricos publicados em periódicos da área de biblioteconomia e ciências da informação (1990 - 2005). Perspectivas em Ciências da Informação, v. 12 n. 3, p. 2-20, set/dez.

MOURA, G. D.; DALLABONA, L. F.; LAVARDA, C. E. F. (2012). O Perfil dos estudos sobre o tema Orçamento publicados nos Congressos Brasileiro de 2005 a 2009. Contabilidade Vista e Revista, v.23 n.1 p.97-125, jan./mar.

MUGNAINI, R.; JANNUZZI, P. M.; QUONIAM, L. Indicadores bibliométricos da produção científica brasileira: uma análise a partir da base Pascal. Ci inf. Brasília, v. 32 n.2, p.123-131, maio/ago. 2004.

OKUBO, Y. (1997). Bibliometric indicators and analysis of research systems: methods and examples. Paris: OCDE.

OLIVEIRA, A. C. P.; ARAGÃO, I. R. B. N. (2011). O perfil das pesquisas em Contabilidade de Custos publicadas nas revistas on-line avaliadas pela coordenação de 
aperfeiçoamento de Pessoal de Nível Superior. Anais... XVIII Congresso Brasileiro de Custos.Rio de Janeiro/RJ.

OLIVEIRA, E. K. F.; BOENTE, D. R. (2012). Análise bibliométrica da produção científica recente sobre contabilidade gerencial. Organização em Contexto, v. 8, n.15, jan./jun.

OLIVEIRA, R. R.; CARVALHO, V. S. C.; ALVES, F. J. S.; LAURENCEL, C. L.; FÉLIX, C. L. (2009). A produção bibliográfica dos programas de mestrado e doutorado em Ciências contábeis sobre Contabilidade de Custos e Contabilidade Gerencial. Anais... In: XVI Congresso Brasileiro de Custos. Fortaleza/CE.

OLIVEIRA, R. R.; CARVALHO, V. S. (2008). A produção Científica sobre Auditoria: um estudo bibliométrico a partir de indicadores da CAPES no Período de 2004 a 2006. Revista Pensar Contábil. v.10, n.42, p. 12-21.

PELEIAS, I. R.; SILVA, G. P.; SEGRETI, J. B., CHIROTTO, A. R. (2007). Evolução do ensino da contabilidade no Brasil: uma análise histórica. Revista contabilidade e Finanças USP, edição 30 anos de doutorado, p.19-32.

PINTO, J.; SILVA, A. J.; FILHO, J. R. T. (2009). Análise bibliométrica de artigos sobre controladoria publicados em periódicos dos programas de pós-graduação em ciências contábeis recomendadas pela Capes. Revista da Associação Brasileira de Custos, Rio Grande do Sul, v. IV, n 1, jan./abr.

ROSA, A. F.; TEIXEIRA, G. M. A.; MENDES, A. C. A.; ABREU, S. M. (2010). Gerenciamento de resultados: Análise Sociométrica e Bibliométrica dos autores de referência. Anais...Congresso USP de Controladoria e Contabilidade, 2010.

ROZA, M. C.; MACHADO, D. G.; QUINTANA, A. C. (2011). Análise bibliométrica da Produção Científica sobre Contabilidade Pública no Encontro de Administração Pública e Governança - ENAPG e na Revista de Administração Pública - RAP, no período de 2004 a 2009. Contexto, v.11 n.20, p.59-72.

SAES, S.G. (2000). Estudo bibliométrico das publicações em economia da saúde, no Brasil 1989-1998. (Dissertação de Mestrado). Programa de Pós-Graduação em Administração, Serviços de Saúde, Faculdade de Saúde Pública Universidade de São Paulo

SANTOS, A. F.; RAUSCH, R. B. (2009). Perícia contábil na Revista de Contabilidade: uma análise bibliométrica do período de 1992 a 2008. Anais...XVI Congresso Brasileiro de Custos. Fortaleza/CE. 
O Perfil da Pesquisa Bibliométrica Publicada nas 19 Edições do Congresso Brasileiro de Custos Marcleide Mendes Barboza, Wellington Dantas de Sousa, João Carlos Hipólito Bernardes do

Nascimento,Juliana Reis Bernardes,Josaias Santana dos Santos

SANTOS, N. A.; LIMA, S. C.; MARTINS, G. A. (2009). Análise do Referencial Bibliográfico de Dissertações do Programa Multiinstitucional de Pós-Graduação em Ciências Contábeis (UFPB, UFPE, UFRN E UNB). Anais... ANANPAD, São Paulo.

SILVA, A. P. F.; NASCIMENTO, A. N.; PINHO, M. A. B; FALK, J. A. (2012). Estudo bibliometrico sobre custo em organizações de construção civil: contribuições do Congresso brasileiro de custos de 1996 a 2010. Anais...XIX Congresso Brasileiro de Custos. Bento Gonçalves/RS.

SILVA, A. C. B.; OLIVEIRA, E. C.; FILHO, J. F.R. (2005). Uma comparação entre os periódicos 1989/2001 E 2001/2004. Revista Contabilidade \& Finanças - USP, n.39, p.20-32, set/dez.

SOUZA, C. D.; FARIA, L. I. L. (2011). Indicadores bibliométricos de produção científica: contribuições para políticas públicas na Citricultura Brasileira. In: IV Simpósio Nacional de Tecnologia e Sociedade.

SPLITTER, K.; ROSA, C. A. (2012). Genealogia dos trabalhos bibliométricos em contabilidade. Anais do Congresso USP Controladoria e Contabilidade, São Paulo, SP, Brasil.

THEÓPHILO, C. R.; IUDÍCIBUS, S. (2005). Uma análise critico-epistemológica da produção científica em Contabilidade no Brasil. Encontro da Associação Nacional de Pós-Graduação e Pesquisa em Administração. 2005, Brasília, ANPAD.

VANTI, N. A. P. (2002). Da bibliometria à webometria: uma exploração conceitual dos mecanismos utilizados para medir o registro da informação e a difusão do conhecimento. Ciência da Informação, Brasília, v.31, n.2, p.52-62.

VEY, I. H.; VENTURINI, J.; MAEHLER, A. E.; PEREIRA, B. A. D.; BELTRAME, R. (2008). Delineamento da área de ensino e pesquisa em contabilidade do Congresso de controladoria e contabilidade da USP. XV Congresso Brasileiro de Custos. Curitiba/PR.

VIEIRA, P. S.; HORI, M.; GUERREIRO, R. (2008). A construção do conhecimento nas áreas de Controladoria, logística e gerenciamento da cadeia de suprimentos: um estudo Bibliométrico. Anais...XV Congresso Brasileiro de Custos. Curitiba/PR, 2008.

Data de Submissão: 17/07/2015

Data de Aceite: 13/01/2016 